02

\title{
Квазиупругое рассеяние света в конгруэнтных кристаллах ниобата лития
}

\author{
(C) А.А. Аникьев ${ }^{1}$, М.Ф. УМаров ${ }^{2}$ \\ ${ }^{1}$ Московский государственный технический университет им. Н.Э. Баумана, \\ 105005 Москва, Россия \\ ${ }^{2}$ Вологодский государственный университет, \\ 160000 Вологда, Россия \\ e-mail: aaanikyev@mail.ru
}

Поступила в редакцию 14.12.2016 г.

В окончательной редакции 19.03.2018 г.

Получены спектры комбинационного рассеяния света в области частот $5-75 \mathrm{~cm}^{-1}$ в образцах ниобата лития с различной степенью несовершенства структуры. Показано, что интенсивность квазиупругого рассеяния света на крыле линии Релея проявляет экспоненциальную зависимость от концентрации крупномасштабных дефектов в образцах. Построены калибровочные кривые зависимости интенсивности квазиупругого рассеяния при низких частотах от акустической добротности.

DOI: $10.21883 /$ OS.2018.07.46261.358-16

\section{Введение}

Нелинейные сегнетоэлектрические монокристаллы ниобата лития в настоящее время широко применяются в приборах твердотельной электроники в качестве модуляторов, удвоителей частоты лазерного излучения, резонаторов, акустооптических фильтров, амплитуднофазовых модуляторов и дефлекторов световых пучков. Однако в ряде случаев применение ниобата лития как преобразователя лазерного излучения, а также в качестве акустооптического фильтра сдерживается изза эффекта фоторефракции и снижения акустической добротности, вызванных предположительно как внедренными примесями в процессе выращивания, так и собственными дефектами структуры $[1,2]$. В связи с этим исследованию влияния примесей и дефектов на основные оптические [3,4] и акустические [5-8] свойства ниобата лития различными методами в последнее время уделяется значительное внимание.

Одним из наиболее чувствительных методов к дефектам стехиометрии, примесям, макродефектам является колебательная спектроскопия, в частности комбинационное рассеяние света (КРС). В недавних работах по изучению параметров линий КРС в кристаллах ниобата лития стехиометрического и конгруэнтного составов [9-11] было показано, что такие параметры, как уширение и интенсивность спектральных линий, а также проявление дополнительных линий в спектрах, не относящихся к фундаментальным колебаниям, связано с различным составом исходной шихты, примесями и дефектами стехиометрии. На проявление особенностей в спектрах КРС ниобата лития, связанных с происхождением исходной шихты, ее составом и особенностями выращивания кристаллов, указывалось еще в работе [12], где анализировалось низкочастотное рассеяние света в ниобате лития при температурах $300-1460 \mathrm{~K}$ и в окрестности фазового перехода. В работе [13] была исследована связь между интенсивностью низкочастотной полосы в области $120 \mathrm{~cm}^{-1}$, происхождение которой дискутируется, и акустической добротностью образцов ниобата лития, вырезанных из булей различной степени несовершенства. При этом была установлена корреляция между интенсивностью указанной полосы и добротностью образцов, полученной радиотехническим резонансным методом на частоте $300 \mathrm{MHz}$. Однако в работе [13] не было уделено должного внимания условиям выращивания образцов ниобата лития, на которых проведены измерения добротности. Кроме того, не были изучены параметры квазиупругого рассеяния света на образцах с различной добротностью, в то время как релеевское рассеяние света на дефектах и несовершенствах структуры имеет свои характерные черты.

Получение достоверных результатов возможно только в том случае, если вещество исследуется комплексом доступных методов на одних и тех же образцах. Расхождение в интерпретации колебательных спектров ниобата лития на протяжении почти 50 лет связано в основном с тем, что исследования проводились на образцах различного качества, полученных в разных лабораториях и выращенных при различных условиях из шихты различного географического происхождения. Кроме того, в исследованиях, связанных с методами выращивания оптически чистых, относительно бездефектных кристаллов с контролируемыми примесями, синтез шихты проводится разными методами.

В данной работе, являющейся естественным продолжением работы [13], излагаются результаты исследований связи параметров квазиупругого рассеяния света со степенью дефектности структуры кристаллов ниобата лития конгруэнтного состава, при этом несовершенства структуры образцов связываются с их акустической добротностью. 


\section{Подготовка образцов и методика эксперимента}

В настоящее время освоена методика выращивания кристаллов ниобата лития хорошего оптического качества из конгруэнтного расплава [14]. В таких кристаллах с отношением концентраций атомов лития к атомам ниобия $[\mathrm{Li} / \mathrm{Nb}]=0.946$ наряду с дефицитом атомов лития имеется большое количество собственных точечных и макродефектов, связанных с условиями выращивания, составом и происхождением шихты. Если не контролировать исходную шихту на наличие примесей, то кристаллы ниобата лития можно назвать достаточно „Грязными“ кристаллами с точки зрения наличия в них точечных дефектов (таких как атомы примеси, вакансии лития, ниобия, квазисвободные электроны) и макродефектов, связанных с условиями выращивания: степенью контроля осевого и радиального градиента температуры, скоростью вытягивания и вращения затравки, режимов отжига и монодоменизации готовых образцов.

Исследованные в настоящей работе монокристаллы были выращены в воздушной атмосфере методом Чохральского из расплава конгруэнтного состава при изменении одного из режимов выращивания - скорости вытягивания затравки из расплава. Состав шихты не контролировался на количество и концентрацию примесей. Образцы ниобата лития вырезались из буль, выращенных при различных скоростях вытягивания затравки из расплава. Скорости вытягивания варьировали в пределах от 5 до $23 \mathrm{~mm} / \mathrm{h}$. Известно [14], что с возрастанием скорости вытягивания затравки возрастает плотность дислокаций в кристаллах ниобата лития. Этот факт подтверждается также при измерении коэффициента поглощения ультразвука — наибольшую добротность имели образцы, выращенные при самой низкой скорости вытягивания, и наименьшую добротность - при максимальной скорости вытягивания. Остальные условия выращивания были идентичны: скорость вращения затравки составляла 45 rotations per minute (rpm), осевые градиенты температуры поддерживались одинаковыми в пределах ошибки измерений и составляли величину $3-5^{\circ} \mathrm{C} / \mathrm{mm}$.

Образцы для исследований имели форму прямоугольных параллелепипедов размерами $10 \times 4 \times 5 \mathrm{~mm}$ с ребрами, ориентированными параллельно соответственно кристаллографическим осям $X, Y, Z$ с точностью не хуже $1^{\circ}$. Ось $Z$ совпадала с оптической осью кристалла и направлением вектора спонтанной поляризации. Грани образцов полировались. Для измерений акустического поглощения методом рассеяния Брэгга света на звуке все грани полировались с оптическим качеством; попарно параллельные грани, а также грани, перпендикулярные оптической оси и волновому вектору распространения звука, имели плоскостность не хуже 0.5 кольца; непараллельность этих граней была не более $10^{\prime \prime}$.

Спектры КРС возбуждались аргоновым лазером на длине волны $514.5 \mathrm{~nm}$ мощностью $2 \mathrm{~mW}$ и регистриро- вались с разрешением $1-2 \mathrm{~cm}^{-1}$ на модернизированном двойном монохроматоре ДФС-24 с накоплением сигнала и автоматической обработкой спектра с использованием пакетов программ LabSpec и Origin 8.0. Точность определения частот линий составляла $\pm 2 \mathrm{~cm}^{-1}$, интенсивности - 6\%.

Акустическая добротность образцов измерялась радиотехническим резонансным методом на частоте $300 \mathrm{MHz}$ и методом рассеяния Брэгга света на звуке $[15,16]$ на частотах 500, 700 и $900 \mathrm{MHz}$. Для возбуждения продольных и сдвиговых упругих волн в исследуемых образцах применялись нерезонансные торцевые преобразователи из ниобата лития, имеющие соответственно $Z$-срезы и $+163^{\circ} / Y$-срезы. Торцевые преобразователи имели форму цилиндров длиной $10 \mathrm{~mm}$ и диаметром $6 \mathrm{~mm}$. Преобразователи обрабатывались также по оптическим стандартам. В качестве источника сканирующего излучения был использован гелийнеоновый лазер на длине волны $632.8 \mathrm{~nm}$. Прием и усиление дифрагирующего света производился с помощью фотоэлектронного умножителя.

Поскольку поглощение сдвиговых волн в ниобате лития примерно в 20 раз выше поглощения продольных звуковых волн, измерение акустического поглощения для сдвиговых волн в настоящей работе проводилось в режиме бегущей волны. Коэффициент затухания в режиме бегущих волн оценивался по степени уменьшения интенсивности брэгговской дифракции света по мере перемещения лазерного луча по кристаллу на определенное расстояние:

$$
\alpha=10 \lg \left(\frac{I_{1}}{I_{2}}\right) /\left(x_{1}-x_{2}\right)\left[\frac{d b}{c m}\right],
$$

где $I_{1}, I_{2}$ - интенсивности рассеяния соответственно в точках $x_{1}$ и $x_{2}$ кристалла.

Для продольных волн интенсивность дифрагированного света измерялась дважды в импульсном режиме генерации акустической волны в одной точке на образце через промежуток времени, меньший времени следования импульсов в режиме стоячей волны. Поскольку на высоких частотах возбуждались собственные акустические резонансы образцов ниобата лития [17], измерения проводились на частотах антирезонансов.

Добротность образцов вычислялась по соотношению

$$
Q=\pi v /(\alpha v),
$$

где частота ультразвука $v$ известна с высокой точностью, а скорость звука в образце $v$ измеряется по углу дифракции Брэгга.

\section{Результаты и их обсуждение}

В нецентросимметричной фазе пространственная группа симметрии ниобата лития $C_{3 v}^{6}(R 3 c)$ с двумя формульными единицами в примитивной ячейке. Фактор-групповой анализ дает следующее колебательное 
представление по типам симметрии в центре зоны Бриллюэна [18]:

$$
\Gamma=5 A_{1}+5 A_{2}+10 E,
$$

при этом по одному из колебаний $A_{1}$ - и $E$-типов симметрии принадлежат акустическим модам, псевдоскалярные колебания типа $A_{2}$ неактивны в КРС и ИК спектрах. Благодаря отсутствию центра симметрии в пространственной группе кристалла колебания $A_{1}$ - и $E$-типов симметрии являются дипольно-активными, т.е. расщепляются в электрическом поле на продольные и поперечные. Согласно компонентам тензора КРС для кристаллов данной группы симметрии, полносимметричные поперечные колебания могут наблюдаться в прямоугольной геометрии $X(Z Z) Y$ и геометриях обратного рассеяния $X(Z Z) \bar{X}$ и $Y(Z Z) \bar{Y}$, а продольные - в геометриях обратного рассеяния $Z(X X) \bar{Z}$ и $Z(Y Y) \bar{Z}$.

На рис. 1 приведены низкочастотные $\left(5-200 \mathrm{~cm}^{-1}\right)$ спектры КРС конгруэнтных кристаллов ниобата лития с различными значениями добротности в геометрии рассеяния, соответствующей возбуждению полносимметричных колебаний. Приведенные значения добротностей образцов были определены из коэффициентов поглощения для сдвиговых акустических волн с направлением распространения вдоль оптической оси $Z$, измеренных на частоте $300 \mathrm{MHz}$ радиотехническим методом.

Отметим, что, как видно из рис. 1 , наблюдается слабая полоса типа $E$ с частотой $v=153 \mathrm{~cm}^{-1}$, запрещенная правилами отбора при $X(Z Z) Y$-геометрии рассеяния, но очень интенсивная в других геометриях эксперимента; ее появление в первых работах [12] объяснялось изменением показателя преломления кристалла под действием лазерного излучения. Однако в стехиометрических образцах ниобата лития, по данным работы [9], данная линия отнесена к фундаментальным колебаниям $E(\mathrm{TO})$ симметрии и в геометрии $X(Z Z) Y$ не наблюдается. В низкочастотной области спектра конгруэнтных кристаллов ниобата лития наблюдается широкая полоса в области частот $100-120 \mathrm{~cm}^{-1}$, которая отсутствует в стехиометрических образцах [9-11]. Форма и спектральное распределение интенсивности этой полосы меняется в поляризационных геометриях, соответствующих колебаниям $A_{1}$ - и $E$-типов симметрии. Происхождение низкочастотного максимума в области $120 \mathrm{~cm}^{-1}$ до настоящего времени является предметом многочисленных обсуждений. В частности, работа [19] была посвящена выяснению природы этой полосы по исследованию низкочастотных спектров КРС кристаллов ниобата лития конгруэнтного состава. При рассмотрении различных моделей ни одной из них не было дано предпочтение, однако наиболее вероятной моделью авторы считают проявление плотности акустических состояний изза нарушения правил отбора по волновому вектору. Наиболее существенным результатом работы [19], на наш взгляд, является наблюдение максимума в области $100-120 \mathrm{~cm}^{-1}$ как в геометрии рассеяния $X(Z Z) Y$, в

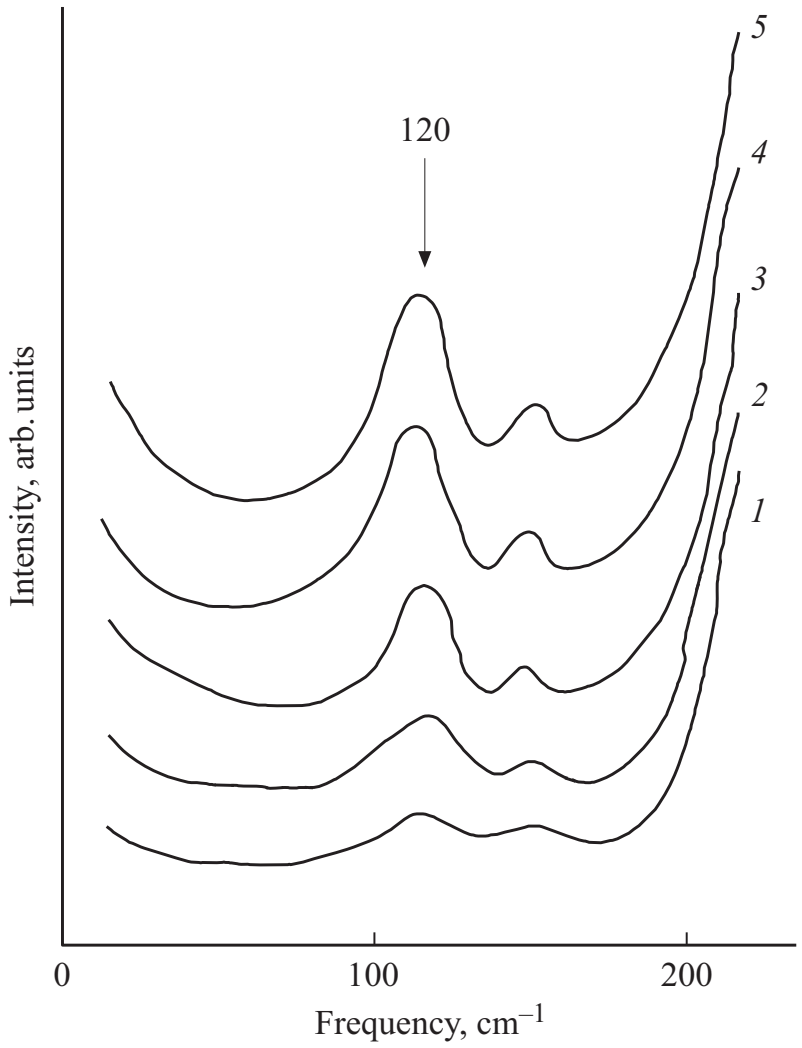

Рис. 1. Низкочастотные спектры КРС в поляризационной геометрии рассеяния $X(Z Z) Y$ в конгруэнтных образцах ниобата лития с различными величинами добротности, определенными из поглощения продольных акустических волн на частоте $300 \mathrm{MHz} .1-Q=1.45 \cdot 10^{4}, 2-Q=1.17 \cdot 10^{4}$, $3-Q=0.85 \cdot 10^{4}, 4-Q=0.52 \cdot 10^{4}, 5-Q=0.35 \cdot 10^{4}$.

которой активны полносимметричные поперечные колебания $A_{1}$-симметрии, так и в геометрии $X(Z X) Y$, в которой активны колебания $E(\mathrm{TO})$-симметрии. При этом форма и спектральное положение максимумов полосы различаются для этих двух поляризационных геометрий. Этот результат находится в согласии с нашим предположением о происхождении полосы в спектре первого порядка как проявлении плотности колебательных акустических состояний суммарных тонов или обертонов в направлении критической точки $\Lambda_{3}$ зоны Бриллюэна, поскольку колебательное представление суммарного тона содержит оба указанных типа симметрии. Полоса в этой области частот в идеальной решетке соответствует резонансному состоянию двух акустических фононов с суммарным волновым вектором, равным нулю [20,21]. Однако ввиду большой величины „расстройки“ резонанса по частотам при низких температурах и малой области задействованных волновых векторов максимум при $100 \mathrm{~cm}^{-1}$ не проявляется. В образцах конгруэнтного состава количество собственных дефектов решетки существенно больше (в сравнении со стехиометрическим образцом), происходит нарушение правил отбора по волновому вектору, при котором в спектрах первого 
порядка разрешены частоты существенно более значительной области волновых векторов, и плотность состояний акустических фононов начинает проявляться в спектрах первого порядка. Причем интенсивность полосы должна возрастать пропорционально концентрации дефектов [22]. В работе [13] была выявлена существенная корреляция между интенсивностью данной полосы и акустической добротностью в конгруэнтных кристаллах ниобата лития, что подтверждает наше предположение о происхождении полосы в области $100-120 \mathrm{~cm}^{-1}$ как проявление акустической плотности состояний в спектрах первого порядка за счет резонанса с фундаментальным полносимметричным колебанием. Условия резонанса значительно улучшаются в дефектном кристалле за счет уширения линии фундаментального колебания с ростом концентрации дефектов.

Еще более значительный вклад дефекты должны давать в квазиупругое и упругое рассеяние света в веществе [23]. Традиционно роль дефектов в рассеянии света изучается в связи со структурными фазовыми превращениями в кристаллах, когда рассматривается несколько механизмов, отвечающих за неустойчивость кристаллической решетки, и дефекты здесь выступают одним из таких возможных механизмов, как например вакансии при плавлении металлов. Однако влияние дефектов на релеевское рассеяние можно изучать и в области устойчивости решетки, когда дефекты наведены искусственно, например путем гамма-облучения кристаллов или изменением условий выращивания, как в настоящей работе. В таком случае изучение этих же образцов в области неустойчивости решетки по отношению, например, к структурному фазовому переходу может внести однозначность в вопрос о механизме потери неустойчивости и о происхождении динамического и статического центральных пиков как в рассеянии света, так и в рассеянии медленных нейтронов. В связи с этим изучение квазиупругого рассеяния света в конгруэнтных кристаллах ниобата лития может послужить некоторым обоснованием не только для правильной интерпретации дополнительных линий в низкочастотном спектре, но и пролить свет на особенности фазового перехода в этих кристаллах.

Мы провели измерения интенсивности в области частот 5-75 cm $\mathrm{cm}^{-1}$ на дискретных частотах в спектрах КРС на образцах ниобата лития с различными добротностями, полученными при измерении акустического поглощения на продольных волнах с частотами 300 , 500, 700 и $900 \mathrm{MHz}$. Характер изменения интенсивности квазиупругого рассеяния света был примерно одинаков для образцов ниобата лития с акустическим поглощением, измеренным на всех указанных частотах возбуждения звука. Особенностью акустического затухания в образцах было отклонение квадратичного закона зависимости затухания от частоты для трех образцов с наименьшей добротностью. Зависимость коэффициента поглощения от частоты для образцов с добротностя-
Таблица 1. Нормированные интенсивности рассеяния света на частотах 50, 20 и $10 \mathrm{~cm}^{-1}$ в конгруэнтных образцах ниобата лития с различными добротностями, измеренными по данным акустического поглощения на продольных волнах на частоте $300 \mathrm{MHz}$

\begin{tabular}{c|r|r|r}
\hline \multirow{2}{*}{$\begin{array}{c}\text { Добротность, } \\
Q \cdot 10^{4}\end{array}$} & \multicolumn{3}{|c}{ Частота, $\mathrm{cm}^{-1}$} \\
\cline { 2 - 4 } & 50 & 20 & 10 \\
\hline 0.35 & 15 & 33 & 82 \\
0.52 & 10 & 20 & 41 \\
0.85 & 7 & 11 & 17 \\
1.17 & 5 & 6 & 10 \\
1.45 & 4 & 5 & 8
\end{tabular}

ми $Q=0.85 \cdot 10^{4}, Q=0.52 \cdot 10^{4}, Q=0.35 \cdot 10^{4}$ описывалась степенным законом с показателем степени от $\sim \omega^{1.5}\left(Q=0.85 \cdot 10^{4}\right)$ до $\sim \omega^{1.3}\left(Q=0.35 \cdot 10^{4}\right)$. Указанная особенность косвенно подтверждает возрастание концентрации крупномасштабных дефектов (плотности дислокаций) с ростом скорости вытягивания затравки из расплава образцов ниобата лития, так как согласно механизму Ахиезера, рост концентрации дефектов приводит к увеличению рассеяния тепловых фононов на дефектах, уменьшению их времени релаксации и, тем самым, к уменьшению затухания звука. Тем не менее изучение частотной зависимости затухания звука требует отдельного рассмотрения - для более точного установления характера зависимостей необходимо измерение поглощения звука при значительно большем наборе частот возбуждения звука, захватывающем и гигагерцовый диапазон.

В табл. 1 приведены измеренные интенсивности (в относительных единицах) крыла линии Рэлея в поляризации рассеяния $X(Z Z) Y$, соответствующей полносимметричным колебательным возбуждениям. Спектральная интенсивность на каждой частоте нормировалась на возбуждающую линию. Экспериментальная погрешность измерения интенсивности составляла 6\%. Данные приведены для образцов с добротностями, соответствующими поглощению продольного звука на частоте $300 \mathrm{MHz}$, распространяющегося вдоль оптической оси кристалла $(Z)$.

По данным табл. 1 были построены зависимости интенсивности рассеяния света на частотах 50, 20 и $10 \mathrm{~cm}^{-1}$ от добротности образцов. Все спектры нормировались на уровень возбуждающей линии. На рис. 2 показаны зависимости интенсивности фонового рассеяния от добротности образцов на указанных частотах квазиупругого рассеяния. Аппроксимация эмпирических данных с наибольшей достоверностью описывается экспоненциальным законом вида

$$
I(Q)=I_{0}+A \exp (-B Q) .
$$

Значения параметров аппроксимации с соответствующими погрешностями приведены в табл. 2. 
Таблица 2. Параметры аппроксимации эмпирической зависимости интенсивности рассеяния света на частотах 50,20 и $10 \mathrm{~cm}^{-1}$ от величины добротности образцов ( $D$ - достоверность аппроксимации)

\begin{tabular}{c|c|c|c|c|c|c|c}
\hline \multirow{2}{*}{$\begin{array}{c}\text { Частота, } \\
\mathrm{cm}^{-1}\end{array}$} & \multicolumn{6}{|c|}{ Параметры аппроксимации законом $I(Q)=I_{0}+A \exp (-B Q)$} \\
\cline { 2 - 8 } & $I_{0}$ & $\begin{array}{c}S_{0}, \\
\text { Стандартная } \\
\text { ошибка } I_{0}\end{array}$ & $A$ & $\begin{array}{c}S_{A}, \\
\text { Стандартная } \\
\text { ошибка } A\end{array}$ & $B$ & $\begin{array}{c}S_{B}, \\
\text { Стандартная } \\
\text { ошибка } B\end{array}$ & $D$ \\
\hline 50 & 3.84083 & 0.8015 & 29.7814 & 6.2788 & 2.8616 & 0.6777 & 0.98037 \\
20 & 4.33746 & 1.046 & 87.7768 & 11.899 & 3.2243 & 0.4161 & 0.99347 \\
10 & 8.34468 & 0.99984 & 370.115 & 34.729 & 4.6218 & 0.2698 & 0.99832
\end{tabular}

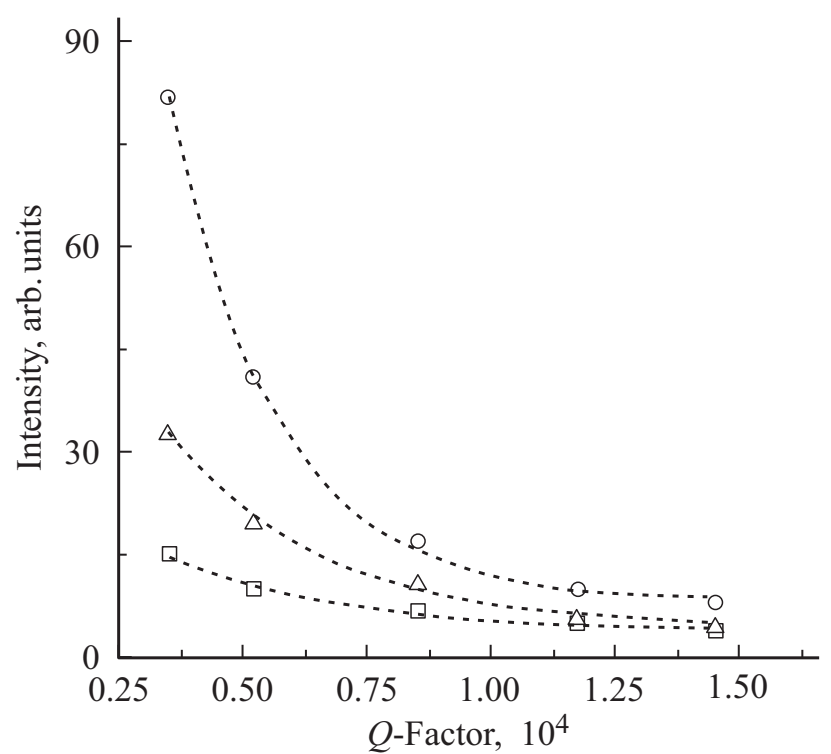

Рис. 2. Интенсивность рассеяния света на частотах $50 \mathrm{~cm}^{-1}$ (квадраты), $20 \mathrm{~cm}^{-1}$ (треугольники) и $10 \mathrm{~cm}^{-1}$ (кружки) крыла линии Рэлея в образцах ниобата лития с добротностями, значения которых приведены в табл. 1 .

Аппроксимация данных по рассеянию проводилась также и степенным законом. Однако достоверность аппроксимации степенным законом ниже, а ошибки определения параметров выше, чем у использованного нами экспоненциального приближения. Необходимо отметить, что точность аппроксимации возрастает при уменьшении частоты квазиупругого рассеяния. Для одноосного сегнетоэлектрика ниобата лития характерны крупномасштабные дефекты: границы зерен, дислокации, линии дислокаций, параллельных оси спонтанной поляризации. Кроме того, при концентрациях дефектов выше некоторой критической дальнодействующие силы могут приводить к образованию сверхструктуры - упорядочению дефектных областей чаще в направлении оси спонтанной поляризации или близкой к ней. Появление такой субблочной структуры и способы повышения добротности за счет повышения уровня возбуждения преобразователя высокочастотным электрическим напряжением изучались, например, в работе [24]. Естественно поэтому ожидать роста интенсивности рассеяния света на низких частотах, где основной вклад дает квазиупругое рассеяние света на крупномасштабных неоднородностях.

Как видно из рис. 2, наиболее сильный экспоненциальный рост интенсивности рассеяния с ростом количества дефектных областей наблюдается на частоте $10 \mathrm{~cm}^{-1}$, причем точность приближения существенно возрастает с уменьшением частоты на крыле квазиупругого рассеяния. Следовательно, как параметры двухчастичной акустической зоны, так и интенсивность квазиупругого рассеяния могут служить количественными признаками степени дефектности структуры. Причем построение калибровочной кривой для определения добротности при комнатной температуре из спектров рассеяния света можно проводить двумя способами: по интенсивности рассеяния линии резонанса акустических фононов на частоте $120 \mathrm{~cm}^{-1}$, как было показано в работе [13], так и по интенсивности квазиупругого рассеяния на низких частотах по соотношению (3). Таким образом, полученные результаты позволяют по спектрам КРС оценить качество структуры кристалла.

Особенности резонансного взаимодействия двухчастичной зоны и фундаментального колебания в присутствии дефектов структуры является задачей, которая требует дальнейшего рассмотрения. Проявление таких взаимодействий желательно исследовать на образцах различной добротности при разных температурах, включая температуру структурного перехода, что является предметом последующих экспериментов.

\section{Заключение}

Таким образом, нами установлено, что интенсивность квазиупругого рассеяния света в конгруэнтных кристаллах ниобата лития является весьма чувствительным индикатором степени дефектности данных кристаллов. Учитывая тот факт, что условия выращивания образцов ниобата лития при различных скоростях вытягивания затравки из расплава приводят к увеличению плотности дислокаций, можно с большой долей вероятности сделать заключение о преобладающем влиянии дислокаций на поглощение звука и релеевское квазиупругое рассеяние света в ниобате лития. Рассматривая зависимость 
интенсивности рассеяния на частоте $10 \mathrm{~cm}^{-1}$ (рис. 2) от добротности образцов как калибровочную кривую для определения добротности из спектральных параметров квазиупругого рассеяния света, можно предложить альтернативный способ оценки качества кристаллов ниобата лития с высокой точностью. Данная методика оценки добротности позволит избежать трудоемких операций по изготовлению пьезорезонаторов, необходимых для прямого измерения добротности радиотехническим методом. Исследование фазовых переходов в образцах ниобата лития с различной добротностью позволит также оценить вклад дефектов в механизм образования центрального пика и вклад акустических фононов в динамический центральный пик, наблюдаемые в спектрах рассеяния света сегнетоэлектрических кристаллов.

\section{Список литературы}

[1] Wong K.K. Properties of Lithium Niobate. London, UK: INSPEC-The Institution of Electrical Engineers, 2002. 143 p.

[2] Gunter P., Huignard J.P. Photorefractive Materials and Their Applications. Part 1. Berlin: Springer-Verlag, 2006. 243 p.

[3] Volk T., Wohlecke M. Lithium Niobate. Defects, Photorefraction, and Ferroelectric Switching. Berlin: Springer, 2008. $250 \mathrm{p}$.

[4] Сидоров Н.В., Волк Т.Р., Маврин Б.Н., Калинников В.Т. Ниобат лития: дефекты, фоторефракция, колебательный спектр, поляритоны. М.: Наука, 2003. 255 с.

[5] Владимирцев Ю.В., Голенищев-Кутузов А.В. // ФТТ. 1980. T. 22. № 1. C. 217-218.

[6] Golenishchev-Kutuzov V.A., Glebova N.N., Migachev S.A., Vladimirzev Y.V. // Ferroelectrics. 1985. V. 64. Iss. 1. P. 209 214.

[7] Li-jie, Dransfeld K. // Zeitschrift fur Phys. B. 1987. V. 68. Iss. 1. P. 169-174.

[8] Akhmedzhanov F., Juraev F. Attenuation of Acoustic Waves in Lithium Niobate Crystals with Impurities. // Société Françaised' Acoustique. Acoustics 2012. Nantes, France, 2012.

[9] Сидоров Н.В., Яничев А.А., Палатников М.Н., Габаин А.A. // Опт. и спектр. 2014. Т. 116. № 1. С. 99-108.

[10] Сидоров Н.В., Палатников М.Н. // Опт. и спектр. 2016. T. 121. № 6. C. 907-915.

[11] Сидоров Н.В., Палатников М.Н., Габриэлян В.Т., Чуфырев П.Г., Калинников В.Т. // Неорганические материалы. 2007. T. 42. № 2. C. 1-8.

[12] Okamoto Y., Wang Pin-chu, Scott J.F. // Phys. Rev. B. 1985. V. 32. N 10. P. 6787-6792.

[13] Умаров М., Грузиненко В., Втюрин А.Н., Ходжибаев А. // Компоненты и технологии. 2010. № 6. С. 138-140.

[14] Кузьминов Ю.С. Электрооптический и нелинейно-оптический кристалл ниобата лития. М.: Наука, 1987. 264 с.

[15] Леманов В.В., Смоленский Г.А. // УФН. 1972. Т. 108. Вып. 3. С. 465-500.

[16] Гуляев Ю.В., Проклов В.В., Шкердин Г.Н. // УФН. 1978. Т. 124. Вып. 1. С. 61-107.

[17] Ogi Hirotsugu, Kawasaki Yasunori, Hirao Masahiko, Ledbetter Hassel. // J. Appl. Phys. 2002. V. 92. N 5. P. 24512456.

[18] Гилсон Т., Хендра П. Лазерная спектроскопия КР в химии. М.: Мир, 1973. 308 c.
[19] Суровцев Н.В., Малиновский В.К., Пугачев А.М., Шебанин А.П. // ФТТ. 2003. Т. 45. № 3. С. 505-512.

[20] Аникьев А.А., Горелик В.С., Умаров Б.С. // Препринт ФИАН СССР. 1984. № 154. М. 24 c.

[21] Аникьев A.A. // Инженерный журнал. Наука и инновации. 2013. Вып. 7 (19). [Электронный ресурс] Режим доступа: http://www.engjournal.ru/articles/837/837.pdf

[22] Кривоглаз М.A. Теория рассеяния рентгеновских лучей и тепловых нейтронов в неидеальных кристаллах. М.: Наука, 1967. 336 с.

[23] Jackle J. // Amorphous Solids: Low-Temperature Properties / Ed. by Phillips W.A. Berlin: Springer, 1981. P. 278.

[24] Островский И.В., Надточий Ф.Б., Коротченков О.А., Никандрова М.В. // ЖТФ. 2003. Т. 73. Вып. 10. С. 97-100. 